\title{
HPLC-DAD analysis of Hyssopus Cuspidatus Boriss extract and mensuration of its antioxygenation property
}

\author{
Lu Zhao ${ }^{1}$, Zhihong $\mathrm{Ji}^{2}$, Keao Li ${ }^{2}$, Bo Wang ${ }^{3}$, Ya Zeng $^{4}$ and Shuge Tian ${ }^{4^{*}}$ (D)
}

\begin{abstract}
Background: Hyssopus cuspidatus Boriss has been used as an important ethnomedicinal plant for long to eliminate phlegm, relieve cough and as well as having antibacterial, antioxygenation, and antitumor activities. In this study, the polyphenol contents, flavonoid contents, free radical scavenging assay and animal antioxygenation property assay of ethanol extract of $H$. cuspidatus were measured.
\end{abstract}

Methods: This study determined the total polyphenol and flavonoid contents in H. cuspidatus by UV-VIS. Caffeic, ferulic, and rosmarinic acids were measured using HPLC-DAD. Free radical scavenging assay of $\mathrm{H}$. cuspidatus was studied by colorimetric method. Animal antioxygenation property assay of H. cuspidatus was studied with mice by biochemical assay kits.

Results: The total polyphenol and flavonoid contents of H. cuspidatus in 2017, 2018, 2019 were determined and the contents of H. cuspidatus in 2019 was the highest. In addition, rosmarinic acid was the phenolic acid with the highest content in $\mathrm{H}$. cuspidatus. Compared with those of DPPH free radical, hydroxyl free radical, and superoxide anion free radical, the scavenging ability of $H$. cuspidatus of ABTS free radical was stronger, the average $I_{50}$ value was $0.0245 \mathrm{mg} / \mathrm{mL}$. In animal antioxygenation property experiment, the model group was successfully established with decreased activities of SOD, CAT, and GSH-px and increased content of MDA. The ethanol extract of H. cuspidatus increased the activities of SOD, CAT, and GSH-px and reduced the content of MDA. Each group of samples and the ascorbic acid positive control group showed significant differences in the results of free radical scavenging and animal antioxygenation property experiments $(P<0.05)$.

Conclusions: These results suggest that $H$. cuspidatus exerts an antioxygenation property, which can be attributed to the contents of total polyphenol and flavonoid. Given its strong antioxygenation property, H. cuspidatus can be used as a new natural antioxidant in food preservation and disease treatment.

Keywords: Hyssopus cuspidatus Boriss, Total polyphenol and flavonoid, HPLC-DAD, Free radical scavenging, Antioxygenation property

\section{Background}

Plants contain a variety of bioactive metabolites that are often used in drug development, flavoring, fragrance, and other functional products because of their antioxygenation, anti-inflammatory, and antibacterial activities [1]. Hyssopus has been cultivated in Europe since ancient

* Correspondence: tianshuge@hotmail.com

${ }^{4}$ College of TCM, Xinjiang Medical University, Urumqi, China

Full list of author information is available at the end of the article times, and it is popular as a flavoring and medicinal plant in India. It is planted as a fragrance material in high-altitude places all over the tropics [2]. Hyssopus cuspidatus Boriss (H. cuspidatus) belongs to Labiatae, is a perennial herb or subshrub, and its dry aboveground part have been commonly used in folk medicine [3]. Although it has been cultivated in many areas of China, some wild herbs are also widely distributed in Tianshan, Altay, western Junggar, Pamir, and Kunlun Mountains 
[4]. The whole herb contains volatile oil, which is the most studied functional natural component at present [5]. Aside from the volatile oil, polyphenols, flavonoids, triterpenes, alkanes, and steroids are also studied as major components [6]. Modern pharmacological research shows that $H$. cuspidatus can reduce or improve airway inflammation, lower blood sugar, eliminate phlegm, and relieve cough, and has many biological activities, such as antibacterial, antioxygenation, and antitumor [7].

Free radical is the direct participants and producers of human diseases, aging and death. The imbalance of free radicals is the root of human diseases and aging [8]. Therefore, as long as the free radical in the body are maintained in the dynamic equilibrium state of generation and elimination, the diseases caused by active oxygen and lipid peroxidation can be resisted $[9,10]$. Antioxidants can directly eliminate excess free radical and effectively prevent or reduce the oxidative damage caused by free radical to aid in the treatment of diseases related to oxidative damage [11, 12]. Natural antioxidants found in plants are popular because of their high efficiency and nontoxicity, and are mainly derived from plant polyphenols and flavonoids [13]. Polyphenols can inhibit the production of free radical and reactive oxygen species (ROS) in metabolism, which is related to the risk of diseases caused by oxidative stress, such as inflammation, cancer, atherosclerosis, and other chronic diseases [14]. Phenolic acid, which is the main component of polyphenols in plant food, can scavenge free radical and is related to anti-cancer and antiinflammatory activities [15]. Flavonoids, which are strong antioxidants abundant in plants, can also effectively scavenge oxygen free radical in the body. The antioxygenation effect of flavonoids can prevent cell degeneration, aging, and cancer. Epidemiology also shows that flavonoids are potential adjuvant therapy for Alzheimer's disease [16].

This study aims to detect the total polyphenol and flavonoid in $H$. cuspidatus samples that were collected in different years and then establish the relationship between the content and the year. High-performance liquid chromatography-diode array detector (HPLC-DAD) was used to analyze the phenolic compounds in $\mathrm{H}$. cuspidatus. Free radical scavenging capacity and animal antioxygenation property of $H$. cuspidatus ethanol extract was tested. This study can serve as a reference to understand the antioxygenation property of H. cuspidatus, provide a database for the comprehensive utilization of natural antioxidants, and lay a foundation for the research of antioxygenation mechanisms.

\section{Methods}

\section{Plant materials}

Three wild batches of $H$. cuspidatus were obtained from Habahe County in Altay (N 48 $09^{\prime} 81.6^{\prime \prime}$, E 86 36' $\left.83.3^{\prime \prime}\right)$ in August 2017, 2018, 2019 during the flowering period. The plant is not endangered, so no permission is required to collect the samples. The plant materials were identified by Yonghe Li, a chief apothecary of the Chinese Medicine Hospital of Xinjiang. The voucher specimens (No.ZY2017081305, No.ZY2018081501, No.ZY2019082006) were deposited at the Traditional Chinese Medicine Ethnical Herbs Specimen Museum of Xinjiang Medical University.

\section{Chemicals and reagents}

[2,2'-azino-bis-(3-ethylbenzo-thiazoline-6-sulfonic acid)] (ABTS free radical), D-galactose and ascorbic acid (VC) were received from Solarbio Science and Technology Co., Ltd. (Beijing, China). LC grade acetonitrile was supplied by Thermo Fisher Scientific Inc. (USA). Caffeic and rosmarinic acids standards were purchased from SIGMA-ALDRICH Co., Ltd. (USA). Ferulic acid was purchased from Yuanye Biotechnology Co., Ltd. (Shanghai, China). 2,2'-diphenyl-1-picrylhydrazyl (DPPH free radical) was purchased from TCI Development Co., Ltd. (Shanghai, China). The biochemical assay kits used for determination of superoxide dismutase (SOD), malondialdehyde (MDA), catalase (CAT) and glutathione peroxidase (GSH-px) were received from Elabscience Biotechnology Co., Ltd. (Wuhan, China). All the chemicals used in the study were of analytical grade.

\section{Extraction method}

$H$. cuspidatus coarse powder was dried in an oven at $60^{\circ} \mathrm{C}$. Extraction was conducted using $2.0 \mathrm{~g}$ of $\mathrm{H}$. cuspidatus coarse powder with $20 \mathrm{~mL}$ of $70 \%$ ethanol at $85^{\circ} \mathrm{C}$ in a water bath reflux device for $1 \mathrm{~h}$ [17]. The samples were extracted twice and filtered. The extract was placed in a $50 \mathrm{~mL}$ bottle for the determination of total polyphenol content (TPC) and total flavonoid content (TFC).

In accordance with the above extraction method, $150.0 \mathrm{~g}$ of $\mathrm{H}$. cuspidatus coarse powders were extracted, and the liquid extract was evaporated to dryness on a water bath. The yield of $H$. cuspidatus ethanol extract in 2019, 2018, 2017 were 10.36, 10.24, and 10.11\%, respectively. Free radical scavenging assay and animal antioxygenation property assay were carried out with the residue as the sample.

One point five gram residue were dissolved in $30 \mathrm{~mL}$ of water and $5 \mathrm{~mL}$ of hydrochloric acid, heated, and then hydrolyzed in a water bath for $30 \mathrm{~min}$ [18]. After cooling, the samples were extracted three times with $20 \mathrm{~mL}$ of ethyl acetate and combined with the upper solution. The ethyl acetate extract was dried with $2.0 \mathrm{~g}$ of anhydrous sodium carbonate. Then, the extract was evaporated to dryness, and the residues were dissolved in 25 $\mathrm{mL}$ of methanol. Thus, the solutions were obtained for HPLC detection. 


\section{TPC assay and TFC assay}

The TPC assay was determined using the colorimetric method with Folin-phenol reagent [19]. In brief, $1 \mathrm{~mL}$ of $H$. cuspidatus extract was added to $0.5 \mathrm{~mL}$ of Folinphenol reagent and $1.5 \mathrm{~mL}$ of sodium carbonate solution $(10 \% \mathrm{w} / \mathrm{v})$. After the immediate addition of $8 \mathrm{~mL}$ pure water, the mixture was left for $10 \mathrm{~min}$ in a water bath at $75^{\circ} \mathrm{C}$. Finally, an ultraviolet-visible (UV-VIS) spectrophoto meter was used to detect the absorbance at 760 $\mathrm{nm}$. The standard curve of the absorbance value of gallic acid concentration solution was then determined. TPC was indicated as $\mathrm{mg}$ of gallic acid equivalent per $\mathrm{g}$ of weight of plant after drying.

The TFC assay was conducted by using the colorimetric method in line with Mellado's report [20]. In brief, $0.5 \mathrm{~mL}$ of $H$. cuspidatus extract was added to $1 \mathrm{~mL}$ of sodium nitrite, left to stand for $6 \mathrm{~min}$, added with $1 \mathrm{~mL}$ of $10 \%$ aluminum nitrate, and then left to stand for $6 \mathrm{~min}$. Then, $10 \mathrm{~mL}$ of $1.0 \mathrm{M}$ sodium hydroxide was added, the volume of water was fixed to $20 \mathrm{~mL}$, and the solution was placed for $15 \mathrm{~min}$. Finally, UV-VIS spectrometry was used to detect the absorbance at $510 \mathrm{~nm}$. The standard curve of the absorbance value of rutin concentration solution was then determined. TFC was indicated as mg of rutin equivalent per $g$ of weight of plant after drying.

\section{HPLC-DAD analysis of phenolic acids}

HPLC-DAD system (Agilent RRLC 1200, USA) was used to separate the phenolic acids of $H$. cuspidatus. The analysis was performed with a Wondasil C18 Herb column $(250 \times 4.6 \mathrm{~mm}, 5 \mu \mathrm{m}$ particle size $)$. The mobile phase comprised $0.2 \%$ phosphoric acid in water (A) and acetonitrile (B) with a flow rate of $1 \mathrm{~mL} / \mathrm{min}$. Gradient elution was used for chromatographic analysis, and the gradient elution procedure was as follows: Phase B increased from 18 to $30 \%$ in $30 \mathrm{~min}$ and then to $18 \%$ in $2 \mathrm{~min}$. Then, the proportionality was maintained for $6 \mathrm{~min}$.

The extraction was injected by an auto sampler, and the injection volume was $10 \mu \mathrm{L}$. The detection wavelength was $325 \mathrm{~nm}$, and the column temperature was $35^{\circ} \mathrm{C}$ for the chromatographic analysis of phenolic acids. A standard solution containing phenol compounds, such as caffeic, rosmarinic and ferulic acids, were employed to identify and quantify the analytes. The molecular structure of the three compounds of caffeic, rosmarinic and ferulic acids in the extract of $H$. cuspidatus extract is shown in Fig. 1. Calibration curves were obtained by injecting six concentrations of mixed standard solutions, and then the sample content was obtained by calculation.

\section{DPPH free radical assay}

The DPPH free radical scavenging assay was carried in accordance with the method described by Vlase et al. with minor modifications [21]. In brief, the $H$. cuspidatus extract was dissolved in 70\% ethanol at different concentrations and mixed with $2 \mathrm{~mL}$ of a freshly prepared ethanol solution of DPPH free radical $(100 \mu \mathrm{M})$. The solution was mixed vigorously and stored in darkness at room temperature for $30 \mathrm{~min}$, and UV-VIS (PERSEE New century T6, China) was used to detect the absorbance at $517 \mathrm{~nm}$. The positive control group was measured with VC. The results were expressed as half maximal inhibitory concentration $\left(\mathrm{IC}_{50}\right)$, which was used to indicate the corresponding concentration of the<smiles>O=C(O)/C=C/c1ccc(O)c(O)c1</smiles>

Caffeic acid<smiles>COc1cc(/C=C/C(=O)O)ccc1O</smiles>

Ferulic acid<smiles>O=C(/C=C/c1ccc(O)c(O)c1)OC(Cc1ccc(O)c(O)c1)C(=O)O</smiles>

Rosmarinic acid

Fig. 1 The chemical structure of caffeic, ferulic and rosmarinic acids 
extract when the antioxygenation free radical scavenging capacity was $50 \%$.

\section{ABTS free radical assay}

The ABTS free radical scavenging assay of the samples was performed in accordance with the method described by Kang et al. with slight modifications [22]. In brief, 2 $\mathrm{mL}$ of $10 \mathrm{mM}$ potassium persulfate solution and $2 \mathrm{~mL}$ of $10 \mathrm{mM}$ ABTS free radical solution were mixed and then stored in the dark for $12 \mathrm{~h}$. Ethanol was added to the mixed solution to make its absorbance value reach $0.700 \pm 0.020$ as ABTS working solution at $736 \mathrm{~nm}$ on the UV-VIS spectra. After that, $2 \mathrm{~mL}$ of $H$. cuspidatus extract or ascorbic acid solution was mixed with $2 \mathrm{~mL}$ of ABTS working solution vigorously and stored in the dark at room temperature for $10 \mathrm{~min}$. The $\mathrm{IC}_{50}$ values of the sample extract were calculated on the basis of the concentration and capacity of free radical scavenging curves.

\section{Hydroxyl free radical assay}

The hydroxyl free radical assay of the samples was carried out in accordance with the method described by $\mathrm{Lu}$ et al. with slight corrections [23]. In brief, $0.5 \mathrm{~mL}$ of 7.5 $\mathrm{mM}$ ferrous sulfate heptahydrate, $0.5 \mathrm{~mL}$ of $7.5 \mathrm{mM}$ salicylic acid, $1 \mathrm{~mL}$ of $H$. cuspidatus extract, and $0.2 \mathrm{~mL}$ of $30 \%$ hydrogen peroxide were mixed and left for $30 \mathrm{~min}$ in a water bath at $37^{\circ} \mathrm{C}$. After being cooled, the absorbance of the sample, blank, and control groups was determined at $510 \mathrm{~nm}$ on the UV-VIS spectrometer.

\section{Superoxide anion free radical assay}

The superoxide anion free radical assay of the samples was performed in accordance with the method reported by Liu et al. with some revisions [24]. In brief, $4.5 \mathrm{~mL}$ of $50 \mathrm{mM}$ Tris-Hydrochloric acid and $1 \mathrm{~mL}$ of $\mathrm{H}$. cuspidatus extract were mixed and left for $15 \mathrm{~min}$ in a water bath at $25^{\circ} \mathrm{C}$. Afterward, $0.4 \mathrm{~mL}$ of $5 \mathrm{mM}$ pyrogallic acid was added and left for $5 \mathrm{~min}$ in a water bath at $25^{\circ} \mathrm{C}$. Subsequently, $0.1 \mathrm{~mL}$ of $8 \mathrm{M}$ hydrochloric acid was added to terminate the reaction. Ultimately, the absorbance of the sample, blank, and control groups was measured instantly at $325 \mathrm{~nm}$ on the UV-VIS spectrometer.

\section{Animal antioxygenation property assay}

The animal antioxygenation property assay was performed in accordance with the method reported by Wang et al. with slight revisions [25]. Male six-week-old Kunming mice weighing 20-23g and were specific-pathogen-free were obtained from the Experimental Animal Center of Xinjiang Medical University. The mice were housed in plastic cages under ambient condition and were allowed free access to food and water. The protocol for the experiments was approved by the Ethics Committee of Experimental Animal
Center of Xinjiang Medical University (IACUC2019101501), Xinjiang, China.

After 3 days of adaptive feeding, the mice were randomly divided into six groups ( $n=8 /$ group): (1) normal control group (NCG): $0.9 \%$ physiological saline $(10 \mathrm{~mL} /$ $\mathrm{kg}$ ); (2) D-galactose model group (DMG): $0.01 \mathrm{~mL} / \mathrm{g} \mathrm{D}$ galactose $(100 \mathrm{mg} / \mathrm{kg})$ and $0.9 \%$ physiological saline; (3) VC positive control group (VCG): VC $(100 \mathrm{mg} / \mathrm{kg})$ and $0.01 \mathrm{~mL} / \mathrm{g}$ D-galactose; (4) low-concentration of $\mathrm{H}$. cuspidatus extract group (LHG): $100 \mathrm{mg} / \mathrm{kg} \mathrm{H}$. cuspidatus extract and $0.01 \mathrm{~mL} / \mathrm{g}$ D-galactose; (5) middleconcentration of $H$. cuspidatus extract group (MHG): $200 \mathrm{mg} / \mathrm{kg} \mathrm{H}$. cuspidatus extract and $0.01 \mathrm{~mL} / \mathrm{g} \mathrm{D}$ galactose; (6) high-concentration of $H$. cuspidatus extract group (HHG): $400 \mathrm{mg} / \mathrm{kg} \mathrm{H}$. cuspidatus extract and $0.01 \mathrm{~mL} / \mathrm{g}$ D-galactose. The administration above continues 3 weeks. All mice were fasted for $24 \mathrm{~h}$ after the last administration, and then about $1 \mathrm{~mL}$ of blood from the fundus vein was collected in a microcentrifuge tube. After allowing to stand, the serum was centrifuged twice at $3500 \times \mathrm{g}$ for $10 \mathrm{~min}$ at $4{ }^{\circ} \mathrm{C}$, and the activities of SOD, MDA, CAT, and GSH-px were measured in accordance with the instructions of the kit. All mice were euthanized by anesthetic. All animal experiments followed the ARRIVE guidelines.

\section{Statistical analysis}

All samples were performed in triplicate, and the standard deviation was calculated. The data were indicated as mean \pm standard deviation (SD) and documented in the respective tables or figures. The data were averaged and analyzed using Statistical Package for the Social Sciences (SPSS19.0, USA) software. First, check whether the data conforms to the normal distribution. When the data accorded with normal distribution, single-factor analysis was used to analyze the data. When the data did not conform to the distribution of positive and negative, a nonparametric test was used to analyze the data. Statistically significant difference was considered at $P<0.05$.

\section{Results}

\section{TPC and TFC determination}

The results showed that the TPC and TFC of H. cuspidatus was $1.34-2.06 \%$ and $3.33-4.48 \%$ (Table 1). It indicated that TFC was higher than TPC in H. cuspidatus. There have some differences among three batches of $H$. cuspidatus about TPC and TFC. The TPC and TFC of H. cuspidatus were highest in 2019 (Table 1). The TPC results of statistical analysis showed that there was a significant difference between $H$. cuspidatus of 2019 and those of 2017 and $2018(P<0.05)$, while there was no significant difference between $H$. cuspidatus of 2017 and 2018. The TFC results of statistical analysis showed that 
Table 1 The TPC and TFC in ethanol extract of H. cuspidatus in different years

\begin{tabular}{lllclll}
\hline Compounds & Regression equation & $r^{2}$ & Linear range $(\mathrm{mg} / \mathrm{ml})$ & Sample & Contents (mg/g) & RSD (\%) \\
\hline TPC & $Y=0.124 X-0.009$ & 0.9987 & $0.002-0.005$ & H. cuspidatus(2017) & $14.198 \pm 0.493$ & 3.47 \\
& & & & H. cuspidatus(2018) & $13.391 \pm 0.381$ & 2.85 \\
& & & & H. cuspidatus(2019) & $20.588 \pm 0.551^{*}$ & 2.68 \\
TFC & Y=11.209X-0.007 & 0.9999 & $0.010-0.060$ & H. cuspidatus(2017) & $36.669 \pm 0.523^{*}$ & 1.43 \\
& & & & H. cuspidatus(2018) & $33.279 \pm 0.693^{*}$ & 2.08 \\
& & & & H. cuspidatus(2019) & $44.847 \pm 1.013^{*}$ & 2.26 \\
\hline
\end{tabular}

Values are presented in mean $\pm \mathrm{SD}, n=3$. ${ }^{*}$ represents the values of different $H$. cuspidatus sample group are significantly different from each other $(P<0.05)$

there were significant differences between any two groups of $H$. cuspidatus $(P<0.05)$ (Table 1$)$.

\section{HPLC-DAD analysis}

The results of HPLC-DAD showed three phenolic acids: caffeic acid (RT $8.65 \mathrm{~min}$ ), ferulic acid (RT $15.55 \mathrm{~min}$ ), and rosmarinic acid (RT $22.81 \mathrm{~min}$ ) (Fig. 2). In the chromatogram of the mixed standard and sample, the peak appeared at the same relative retention time, and the whole wavelength scanning pattern of each compound peak was the same (Fig. 2). These results indicate that the sample does contain caffeic, ferulic, and rosmarinic acids. The results used for compound quantification are shown in Table 2. The content of caffeic, ferulic, and rosmarinic acids were $0.04-0.06 \%, 0.01-0.08$ and $0.12 \%-0.13 \%$ (Table 3 ). The content of rosmarinic acid was the highest. There also have some differences among three batches of $H$. cuspidatus in HPLC-DAD analysis. The content of caffeic, ferulic, and rosmarinic acids in $H$. cuspidatus were highest in 2019 (Table 3). The statistical results showed that the content of caffeic and ferulic acids in any two groups were significantly different $(P<0.05)$. The statistical analysis showed that there was a significant difference between the rosmarinic acid content of $H$. cuspidatus of 2017 and those of 2018 and $2019(P<0.05)$, while there was no significant difference between $H$. cuspidatus of 2018 and 2019 (Table 3).

\section{Free radical scavenging assay}

$\mathrm{IC}_{50}$ is widely used as a parameter to measure antioxygenation property. The scavenging effect of the ethanol extract of $H$. cuspidatus on DPPH free radical, ABTS free radical, hydroxyl free radical and superoxide anion free radical in different years is shown in Fig. 3. The results of four free radical model assays showed that there have some differences among three batches of $H$. cuspidatus in free radical scavenging experiment. The ethanol extract of $H$. cuspidatus in 2019 had the best free radical scavenging capacity. The $\mathrm{IC}_{50}$ values of $\mathrm{DPPH}, \mathrm{ABTS}$, hydroxyl radical, and superoxide anion free radical were $0.0250,0.0219,4.8067$, and $0.2738 \mathrm{mg} / \mathrm{mL}$ of $H$. cuspidatus in 2019, respectively (Fig. 3). The analysis results indicate that the antioxygenation property of the ethanol extract of $H$. cuspidatus from high to low is ABTS free radical scavenging capacity, DPPH free radical scavenging capacity, superoxide anion free radical scavenging capacity, and hydroxyl free radical scavenging capacity. SPSS single-factor analysis showed significant differences
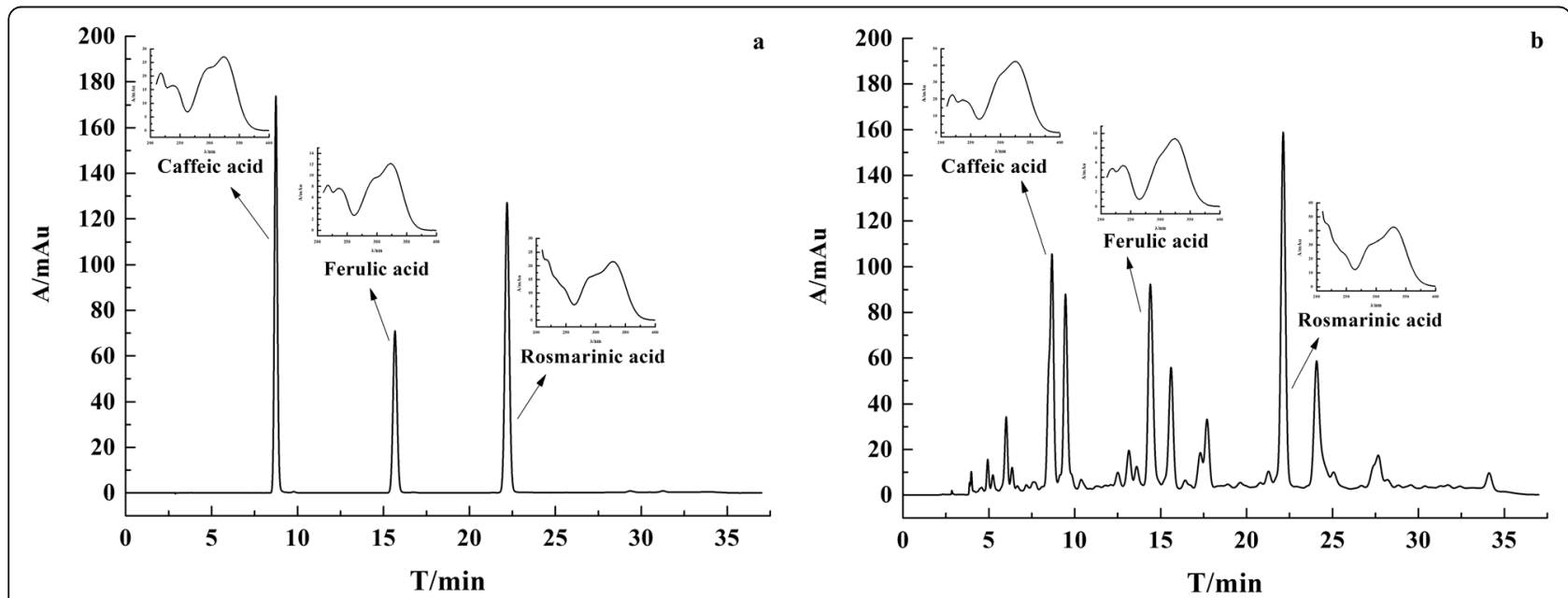

Fig. 2 The HPLC chromatography and UV spectrum of standard and sample. (a represents mixed standard solution and $\mathbf{b}$ represents $H$. cuspidatus ethanol extract) 
Table 2 The quantitative condition of HPLC-DAD

\begin{tabular}{llllll}
\hline Compounds & Regression equation & $r^{2}$ & Linear range $(\mathrm{mg} / \mathrm{mL})$ & $L O D(\mu \mathrm{g} / \mathrm{mL})$ & $\mathrm{LOQ}(\mu \mathrm{g} / \mathrm{mL})$ \\
\hline caffeic acid & $Y=17,218 X+1.14$ & 0.9996 & $0.040-0.242$ & 0.259 & 0.746 \\
ferulic acid & $Y=17,487 X+11.40$ & 0.9999 & $0.022-0.133$ & 0.259 & 0.776 \\
rosmarinic acid & $Y=7728 X+25.16$ & 0.9999 & $0.096-0.576$ & 0.607 & 1.721 \\
\hline
\end{tabular}

between the three ethanol extract of $H$. cuspidatus and the positive control VC $(P<0.01)$. Meanwhile, there are significant differences between any two groups of $\mathrm{H}$. cuspidatus in free radical scavenging experiment $(P<0.01)$ (Fig. 3).

\section{Animal antioxygenation property assay}

The activity of SOD, MDA, CAT and GSH-px in serum of NCG, DMG, VCG, LHG, MHG and HHG mice was shown in Fig. 4. Compared with those in NCG, the activities of SOD, CAT, and GSH-px in DMG decreased while the content of MDA increased, indicating that the aging model was established successfully. For the ethanol extract of $H$. cuspidatus, at the dose of 100, 200 and 400 $\mathrm{mg} / \mathrm{kg}$ body weight treatment groups significantly increased the activities of SOD, GSH-px and CAT and decreased the content of MDA as compared to DMG $(P<$ 0.05) (Fig. 4). The results indicated that the H. cuspidatus extract in 2019 had some antioxygenation property.

All the data was analyzed by single-factor analysis. For the activity of SOD, the antioxygenation effect of LHG is much greater than that of VCG, and there was no significant difference between NCG and VCG. For CAT activity, there was no significant difference between NCG and VCG, but they had significant difference with DMG. In addition, there are significant differences between LHG, MHG and HHG of $H$. cuspidatus $(P<0.05)$ (Fig. 4). The results indicated that $H$. cuspidatus can obviously improve the activity of SOD and CAT. In view of

Table 3 The content of caffeic acid, ferulic acid and rosmarinic acid in H. cuspidatus

\begin{tabular}{llll}
\hline & Compounds & Contents $(\mathrm{mg} / \mathrm{g})$ & RSD $(\%)$ \\
\hline H. cuspidatus(2017) & caffeic acid & $0.403 \pm 0.010^{*}$ & 2.36 \\
& ferulic acid & $0.141 \pm 0.003^{*}$ & 2.10 \\
& rosmarinic acid & $1.238 \pm 0.018^{*}$ & 1.44 \\
H. cuspidatus(2018) & caffeic acid & $0.451 \pm 0.004^{*}$ & 0.99 \\
& ferulic acid & $0.314 \pm 0.002^{*}$ & 0.60 \\
& rosmarinic acid & $1.296 \pm 0.033$ & 2.57 \\
H. cuspidatus(2019) & caffeic acid & $0.634 \pm 0.004^{*}$ & 0.66 \\
& ferulic acid & $0.826 \pm 0.003^{*}$ & 0.35 \\
& rosmarinic acid & $1.305 \pm 0.008$ & 0.58 \\
\hline
\end{tabular}

Values are presented in mean $\pm S D, n=3 .{ }^{*}$ represents the values of different $H$. cuspidatus sample group are significantly different from each other $(P<0.05)$
GSH-px activity, there is significant difference between NCG, VCG, MHG, HHG and DMG, and significant difference between MHG and HHG $(P<0.05)$. However, there was no significant difference between the other groups. For the content of MDA, there was no significant difference between the VCG and sample groups, and no significant difference between LHG, MHG, and HHG. The content of MDA in VCG and sample groups was significantly higher than NCG $(P<0.01)$ (Fig. 4). The results showed that although $H$. cuspidatus had the effect of GSH-px activities and MDA content, the effect was not obvious.

\section{Discussion}

There are differences and overlaps between flavones and polyphenols generally [26, 27]. Polyphenols and flavonoids may be the main functional components of $\mathrm{H}$. cuspidatus to treat diseases. The determination results showed that TPC and TFC account for nearly $6 \%$ of the ethanol extract of $H$. cuspidatus. More flowers and leaves in H. cuspidatus appeared in 2019 because of the high freshness. In 2017 and 2018, less flowers and leaves were appeared because of storage problem. This may be one of the reasons for the higher TPC and TFC of $H$. cuspidatus in 2019. But there is still some biological activity in stem of $H$. cuspidatus in 2017 and 2018, it can be made into some compound preparation.

In HPLC-DAD analysis experiment, the separation effect of mobile phase methanol- $0.1 \%$ formic acid, methanol- $0.2 \%$ phosphoric acid, and acetonitrile- $0.2 \%$ phosphoric acid was screened in the previous research. When the mobile phase was composed of methanol$0.1 \%$ formic acid, the separation effect was not good and many hetero peaks appeared. When the mobile phase was composed of methanol- $0.2 \%$ phosphoric acid, the resolution of caffeic acid was less than 1.5 . When the mobile phase was composed of acetonitrile- $0.2 \%$ phosphoric acid, the target analytes peaks can be separated well. Therefore, acetonitrile- $0.2 \%$ phosphoric acid aqueous solution was chosen as the mobile phase of gradient elution. The experimental results showed that the resolution of the three peaks was over 1.5 , the symmetry factor was more than or equal to 0.8 , and the number of theoretical plates was more than 8000 . It has been reported that the ethyl acetate fraction of the areal part of H. cuspidatus contains caffeic acid and rosmarinic acid [1]. Consistent with the literature, their presence have been analysed by HPLC-DAD this time. The result 


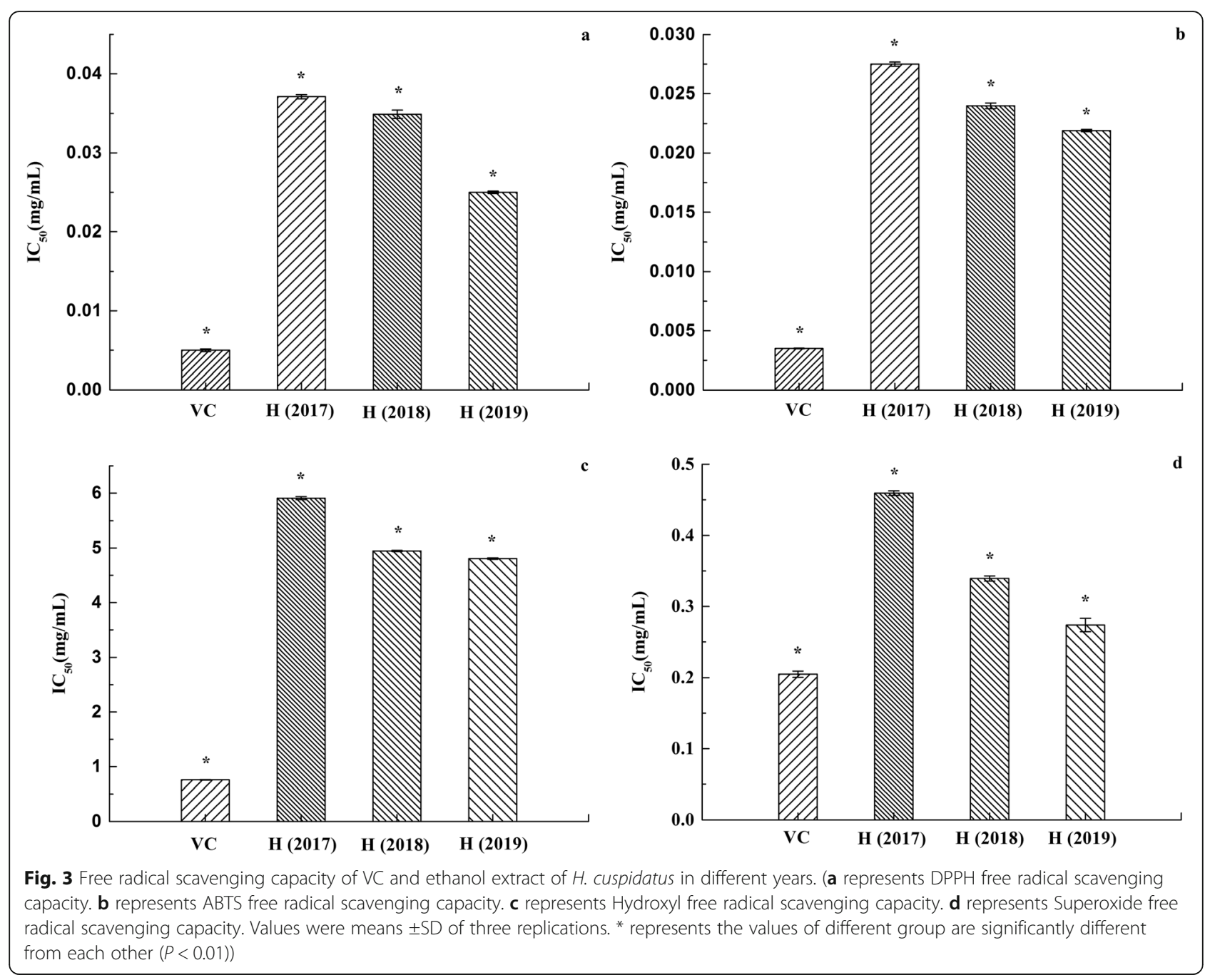

suggests that the content of ferulic acid was directly proportional to the freshness of the samples. The highest content of ferulic acid was achieved in 2019. This result may indicate that ferulic acid existed in the flowers and leaves, whereas rosmarinic acid mainly existed in the stems. In HPLC-DAD analysis experiment, the method of sample pretreatment is complex, which may slightly affect the content of target analytes. The next step is to optimize the pretreatment method of HPLC-DAD.

Through the above experiment, the chemical constituents of H. cuspidatus in 2017, 2018 and 2019 were studied. The experimental results showed that there are differences between different batches of plant materials, that is, the differences between different years of the same plant material. This may be related to the soil environment, atmospheric environment, the method of plant collection and the method of storage. At the same time, the difference of chemical composition of different batches of plant materials may lead to the difference of biological activity. The results of free radical scavenging experiment showed that three batches of $H$. cuspidatus had antioxygenation property, but there also have some differences among them.

The lower the $\mathrm{IC}_{50}$ is, the better the antioxygenation property is; on the contrary, the higher the $\mathrm{IC}_{50}$ is, the worse the antioxygenation property is [28]. It has been reported that the ethyl acetate fraction of $H$. cuspidatus exhibited weak antioxygenation property, and the $\mathrm{IC}_{50}$ value of DPPH free radical was $26.53 \pm 2.32 \mathrm{mg} / \mathrm{mL}$ [1]. In comparison, the free radical scavenging capacity of ethanol extract of $H$. cuspidatus was much stronger, the $\mathrm{IC}_{50}$ value of DPPH free radical was $0.0323 \pm 0.0064 \mathrm{mg} / \mathrm{mL}$, the reason may it contain more polyphenols and flavonoids. The ortho phenolic hydroxyl in the phenolic hydroxyl structure of polyphenols and flavonoids is easily oxidized to quinone structure, which consumes oxygen in the environment [29]. And it has a strong ability to capture free radical, such as ROS, therefore, polyphenols and flavonoids with strong antioxygenation property [30]. The experimental results demonstrate that ABTS free radical 

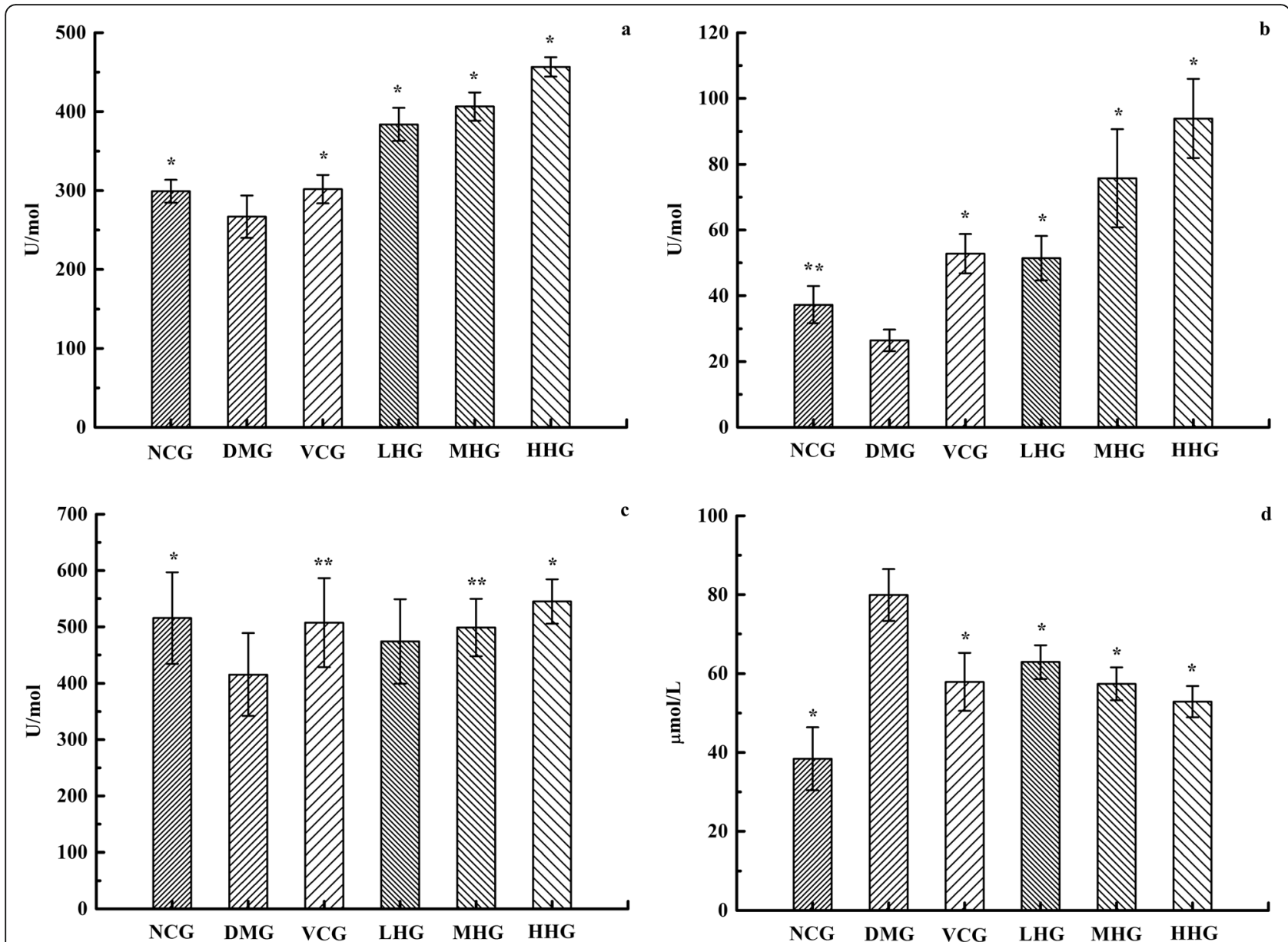

Fig. 4 The activity of SOD, MDA, CAT and GSH-px in serum of NCG, DMG, VCG, LHG, MHG and HHG mice. (a represents the SOD activity. $\mathbf{b}$ represents the CAT activity. $\mathbf{c}$ represents the GSH-px activity. $\mathbf{d}$ represents the content of MDA. Values were means \pm SD of eight samples in a group. * represents the values of different group are significantly different from DMG $(P<0.01) .{ }^{* *}$ represents the values of different group are significantly different from DMG $(P<0.05))$

scavenging capacity, DPPH free radical scavenging capacity, superoxide anion free radical scavenging capacity, and hydroxyl free radical scavenging capacity is directly proportional to TFC and TPC. So the antioxygenation property of its ethanol extract of H. cuspidatus in 2019 is stronger than in the other years studied. The analysis results indicate that the $\mathrm{IC}_{50}$ value of the $\mathrm{DPPH}$ and $\mathrm{ABTS}$ free radical scavenging experiment was smaller. The types of free radicals used in different detection reaction systems, the generation methods of free radicals, the species of the base of free radical damage, and the principle of damage detection are all different [31]. As a result, the results obtained by different antioxygenation detection methods are different.

The oxidation and antioxygenation of human body should be in a relative balance [32]. The human body has a systematic antioxygenation defense mechanism that depends on three important antioxygenation enzymes: SOD, GSH-px, and CAT, which are also important indicators of
ROS generation [10, 33]. In addition, MDA as an indicator of oxidative damage, its content increases with aging, and is widely used in the study of antioxygenation [34]. The animal model of subacute senescence induced by $\mathrm{d}$ galactose has been widely used by scholars at home and abroad for its advantages of low cost, simple operation and stable and reliable results. D-galactose interacts with d-galactose synthase, can produce a large number of ROS, free radicals, leading to a strong oxidative stress reaction in mice, leading to cell membrane damage, and promote aging [35]. In this experiment, the activities of SOD, CAT, and GSH-px in DMG decreased while the content of MDA increased, indicating that the aging model was established successfully. The TPC and TFC in the sample of H. cuspidatus in 2019 are relatively large, and free radical scavenging capacity is relatively good. So, H. cuspidatus in 2019 was selected for animal antioxygenation property experiment. The experiment was divided into LHG, MHG and HHG, the higher the concentration of 
ethanol extract of $H$. cuspidatus were, the more bioactive components it contained. The activity of SOD, CAT and GSH-px is also higher, and on the contrary, the content of MDA is lower. For GSH-px activities and MDA content, there was no significant difference in LHG, MHG and HHG. It may be that GSH-px activities and MDA content are not sensitive to the change of the content of $\mathrm{H}$. cuspidatus extract. Or for those two indicators, there is the phenomenon that the setting of high and medium and low concentrations is unreasonable.

The results of the above experiments indicated that the $H$. cuspidatus extract had antioxygenation property. But the results of free radical scavenging assay and animal antioxygenation property assay are somewhat inconsistent. The free radical scavenging assay is an in vitro experiment, whereas the animal antioxygenation property assay is an in vivo experiment. This may be due to the difference of the factors influencing in vivo and in vitro experiment. Free radical scavenging assay results showed that the antioxygenation property of positive control $\mathrm{VC}$ was stronger than that of $H$. cuspidatus extract. However, in animal antioxygenation property assay, the antioxygenation property of $H$. cuspidatus extract was stronger than VC. In vitro assay revealed that the main factors affecting antioxygenation property are the inherent characteristics of the body and the extraction process itself [36]. Nevertheless, in vivo assay may be affected by other factors, such as digestibility, bioavailability, and metabolism [37]. In vitro assay, in vivo biological effects, for instance, antioxygenation enzyme activity, oxidative metabolism pathway, and the activation or inhibition of antioxygenation and enzyme gene expression, are generally ignored [38]. Consequently, in vivo assay is suitable to assess the antioxygenation potential of compounds.

\section{Conclusions}

In the research, the chemical composition and antioxygenation property of $\mathrm{H}$. cuspidatus were studied. The results showed $2 \%$ total polyphenol and $4 \%$ total flavonoid in $H$. cuspidatus. The contents of caffeic, ferulic and rosmarinic acids were analyzed by HPLC-DAD, among which rosmarinic acid obtained the highest. The results of free radical scavenging assay showed that the ethanol extract of $H$. cuspidatus exerted significant scavenging effects on ABTS, DPPH, hydroxyl, and superoxide anion radical. The results of animal antioxygenation property experiment showed that the ethanol extract of $\mathrm{H}$. cuspidatus can significantly enhance the activities of SOD, CAT, and GSH-px in mouse serum and reduce the content of MDA. In addition, the antioxygenation property of the ethanol extract of $H$. cuspidatus may be related to TPC and TFC. The higher the TPC and TFC are, the better the antioxygenation property is. Given its strong antioxygenation property, $H$. cuspidatus can be used as a new natural antioxidant in food preservation and disease treatment.

\section{Supplementary information}

Supplementary information accompanies this paper at https://doi.org/10. 1186/s12906-020-03016-0.

Additional file 1. : Ethical proof of animal experiment (PDF).

Additional file 2. : Fig. A The HPLC chromatography with mobile phase was composed of methanol-0.1\% formic acid.

Additional file 3. : Fig. B The HPLC chromatography with mobile phase was composed of methanol- $0.2 \%$ phosphoric acid.

\section{Abbreviations}

H. cuspidatus: Hyssopus cuspidatus Boriss; ROS: Reactive oxygen species; HPLC-DAD: High-performance liquid chromatography-diode array detector; ABTS free radical: 2,2'-azino-bis-(3-ethylbenzo-thiazoline-6-sulfonic acid); DPPH free radical: 2,2'-diphenyl-1-picrylhydrazyl; VC: Ascorbic acid; SOD: Superoxide dismutase; MDA: Malondialdehyde; CAT: Catalase; GSHpx: Glutathione peroxidase; TPC: Total polyphenol content; TFC: Total flavonoid content; UV-VIS: Ultraviolet-visible; $I C_{50}$ : Half maximal inhibitory concentration; NCG: Normal control group; DMG: D-galactose model group; VCG: VC positive control group; LHG: Low-concentration of $H$. cuspidatus extract; MHG: Middle-concentration of H. cuspidatus extract; HHG: Highconcentration of H. cuspidatus extract; SD: Standard deviation;

SPSS: Statistical Package for the Social Sciences

\section{Acknowledgements}

Thanks to expert Yonghe Li for identifying the plant Hyssopus cuspidatus Boriss. Thanks to the Animal Experiment Center of Xinjiang Medical University for its help and support.

\section{Authors' contributions}

SGT conceived, designed the experiments, and LZ wrote the paper. The determination of the total polyphenol and flavonoid were performed by $\mathrm{ZHJ}$; HPLC-DAD analysis of phenolic acid components were performed by $L Z$ and $K A L$; Free radical scavenging assay were performed by $L Z$; Animal antioxygenation property assay were performed by BW and YZ; Data analysis by LZ, ZHJ and SGT. All Authors have read and approved the manuscript.

\section{Funding}

The research was funded by horizontal topic (grant number JSHT20150601) and science and technology plan of Urumqi high-tech zone (grant number $\mathrm{KJJH} 2014007)$. The funding agencies played no role in the design of the study and collection, analysis, and interpretation of data and in writing the manuscript, which are fully the responsibilities of the authors. Thanks to fund projects for the financial support.

\section{Availability of data and materials}

Data sharing is not applicable to this article as no datasets were generated or analysed during the current study.

\section{Ethics approval and consent to participate}

The protocol for the experiments was approved by the Ethics Committee of Experimental Animal Center of Xinjiang Medical University (IACUC2019101501), Xinjiang, China. Animal study was carried out in strict accordance with the established institutional guidelines on the use of experimental animals. Consent to participate was not applicable.

Consent for publication

Not applicable.

Competing interests

The authors declare no competing interests. 


\section{Author details}

'College of Pharmacy, Xinjiang Medical University, Urumqi 830011, Xinjiang, China. ${ }^{2}$ Xinjiang Qimu Medical Research Institute, Urumqi 830002, Xinjiang, China. ${ }^{3}$ Experimental Animal Center, Xinjiang Medical University, Urumai 830011, Xinjiang, China. ${ }^{4}$ College of TCM, Xinjiang Medical University, Urumqi, China.

\section{Received: 17 December 2019 Accepted: 6 July 2020}

\section{Published online: 20 July 2020}

\section{References}

1. Shomirzoeva O, Li J, Numonov S, Atolikshoeva S, Aisa HA. Chemical components of Hyssopus cuspidatus Boriss.: isolation and identification, characterization by HPLC-DAD-ESI-HRMS/MS, antioxidant activity and antimicrobial activity. Nat Prod Res. 2020;34(4):534-40. https://doi.org/10. 1080/14786419.2018.1488710

2. Zhang H, Hou Y, Ehbal T, Jiang M, Li F. A comparative analysis of the antiinflammatory effects of Hyssopus cuspidatus Boriss. Essential oil and aspirin on chronic inflammation models in mice. Int J Clin Exp Med. 2019;12:826170.

3. Wu HB, Liu TT, Lian YX, Chen X, Wang WS. Antifeedant activities of secondary metabolites from Hyssopus cuspidatus against Plutella xylostella. Chem Nat Compd. 2018;54:1088-90. https://doi.org/10.1007/s10600-0182562-1.

4. Ablizl P, Cong Y, Musa M, Zhu Y, Kasimu R. Chemical composition of the essential oil of Hyssopus cuspidatus from Xinjiang, China. Chem Nat Compd. 2009;45:445. https://doi.org/10.1007/s10600-009-9309-y.

5. Li HT, Zhao NN, Yang K, Liu ZL, Wang Q. Chemical composition and toxicities of the essential oil derived from Hyssopus cuspidatus flowering aerial parts against Sitophilus zeamais and Heterodera avenae. J Med Plant Res. 2013;7:343-8. https://doi.org/10.5897/JMPR12.475.

6. Yuan F, Liu R, Hu M, Rong X, Bai L, Xu L, He J. JAX2, an ethanol extract of Hyssopus cuspidatus Boriss. Can prevent bronchial asthma by inhibiting MAPK/NF-KB inflammatory signaling. Phytomedicine. 2019;57:305-14. https://doi.org/10.1016/j.phymed.2018.12.043.

7. Zhou X, Hai-Yan G, Tun-Hai X, Tian S. Physicochemical evaluation and essential oil composition analysis of Hyssopus cuspidatus Boriss from Xinjiang, China. Pharmacogn Mag. 2010;6:278. https://doi.org/10.4103/09731296.71790 .

8. Xie K, He X, Chen K, Chen J, Sakao K, Hou DX. Antioxidant properties of a traditional vine tea, Ampelopsis grossedentata. Antioxidants. 2019:8:295. https://doi.org/10.3390/antiox8080295.

9. Valko M, Leibfritz D, Moncol J, Cronin MT, Mazur M, Telser J. Free radicals and antioxidants in normal physiological functions and human disease. Int J Biochem Cell B. 2007;39:44-84. https://doi.org/10.1016/j.biocel.2006.07.001.

10. Nimalaratne C, Wu J. Hen egg as an antioxidant food commodity: a review. Nutrients. 2015;7(10):8274-93. https://doi.org/10.3390/nu7105394.

11. Paran E, Novack V, Engelhard YN, Hazan-Halevy I. The effects of natural antioxidants from tomato extract in treated but uncontrolled hypertensive patients. Cardiovasc Drug Ther. 2009;23:145-51. https://doi.org/10.1007/ s10557-008-6155-2.

12. Liu J, Jia L, Kan J, Jin CH. In vitro and in vivo antioxidant activity of ethanolic extract of white button mushroom (Agaricus bisporus). Food Chem Toxicol. 2013:51:310-6. https://doi.org/10.1016/j.fct.2012.10.014.

13. Batiga S, Valli M, Zeraik ML, Fraige K, Leme GM, Pitangui NS, Bolzani VS. Chemical composition and biological properties of Ipomoea procumbens. Rev Bras Farmacogn. 2019;29(2):191-7. https://doi.org/10.1016/j.bjp.2018.08. 010.

14. Yu M, Chen M, Gui J, Huang S, Liu Y, Shentu H, Zhang Y. Preparation of Chlorella vulgaris polysaccharides and their antioxidant activity in vitro and in vivo. Int J Biol Macromol. 2019;137:139-50. https://doi.org/10.1016/j. ijbiomac.2019.06.222.

15. González-González RM, Barragán-Mendoza L, Peraza-Campos AL, MuñizValencia R, Ceballos-Magaña SG, Parra-Delgado H. Validation of an HPLCDAD method for the determination of plant phenolics. Rev Bras Farmacogn. 2019;29(5):689-93. https://doi.org/10.1016/j.bjp.2019.06.002.

16. Pate KM, Rogers M, Reed JW, Munnik N, Vance SZ, Moss MA. Anthoxanthin polyphenols attenuate $A \beta$ oligomer-induced neuronal responses associated with Alzheimer's disease. CNS Neurosci Ther. 2017:23:135-44. https://doi. org/10.1111/cns.12659.
17. Zeraik ML, Yariwake JH. Quantification of isoorientin and total flavonoids in Passiflora edulis fruit pulp by HPLC-UV/DAD. Microchem J. 2010;96:86-91. https://doi.org/10.1016/j.microc.2010.02.003.

18. Shao Y, Jiang J, Ran L, Lu C, Wei C, Wang Y. Analysis of flavonoids and hydroxylcinnamic acid derivatives in rapeseeds (Brassica napus L. var. napus) by HPLC-PDA-ESI (-)-MS n/HRMS. J Agric Food Chem. 2014;62:2935-45. https://doi.org/10.1021/jf404826u.

19. Benedec D, Hanganu D, Oniga I, Filip L, Bischin C, Silaghi-Dumitrescu R, Vlase L. Achillea schurii flowers: chemical, antioxidant, and antimicrobial investigations. Molecules. 2016;21:1050-62. https://doi.org/10.3390/ molecules21081050

20. Mellado M, Soto M, Madrid A, Montenegro I, Jara-Gutiérrez C, Villena J, Aguilar LF. In vitro antioxidant and antiproliferative effect of the extracts of Ephedra chilensis K Presl aerial parts. J Altern Complement Med. 2019;19(1): 53-63. https://doi.org/10.1186/s12906-019-2462-3.

21. Vlase L, Benedec D, Hanganu D, Damian G, Csillag I, Sevastre B, Tilea I. Evaluation of antioxidant and antimicrobial activities and phenolic profile for Hyssopus officinalis, Ocimum basilicum and Teucrium chamaedrys. Molecules. 2014;19:5490-507. https://doi.org/10.3390/molecules19055490.

22. Kang SH, Jeon YD, Cha JY, Hwang SW, Lee HY, Park M, Kim DK. Antioxidant and skin-whitening effects of aerial part of Euphorbia supine Raf. Extract. J Altern Complement Med. 2018;18(1):256-64. https://doi.org/10.1186/s12906018-2323-5.

23. Lu M, Yan L, Wang B, Tian S. Effect of vibrating-type ultrafine grinding on the physicochemical and antioxidant properties of Turkish galls in Uyghur medicine. Powder Technol. 2018;339:560-8. https://doi.org/10.1016/j. powtec.2018.07.095.

24. Liu F, Liu W, Tian S. Artificial neural network optimization of Althaea rosea seeds polysaccharides and its antioxidant activity. Int J Biol Macromol. 2014 70:100-7. https://doi.org/10.1016/j.ijbiomac.2014.06.040.

25. Wang J, Wang X, He Y, Jia L, Yang CS, Reiter RJ, Zhang J. Antioxidant and pro-oxidant activities of melatonin in the presence of copper and polyphenols in vitro and in vivo. Cells. 2019;8:903-21. https://doi.org/10. 3390/cells8080903.

26. Rojas-Bravo M, Rojas-Zenteno EG, Hernández-Carranza P, Ávila-Sosa R, Aguilar-Sánchez R, Ruiz-López II, Ochoa-Velasco CE. A potential application of mango (Mangiferaindica L. cv Manila) peel powder to increase the total phenolic compounds and antioxidant capacity of edible films and coatings. Food Bioprocess Technol. 2019;12(9):1584-92. https://doi.org/10.1007/ s11947-019-02317-8

27. Atala E, Fuentes J, Wehrhahn MJ, Speisky H. Quercetin and related flavonoids conserve their antioxidant properties despite undergoing chemical or enzymatic oxidation. Food Chem. 2017;234:479-85. https://doi. org/10.1016/j.foodchem.2017.05.023.

28. Yang $\mathrm{CH}$, Li RX, Chuang LY. Antioxidant activity of various parts of Cinnamomum cassia extracted with different extraction methods. Molecules. 2012;17:7294-304. https://doi.org/10.3390/molecules17067294.

29. Woźniak M, Mrówczyńska L, Waśkiewicz A, Rogoziński T, Ratajczak I. The role of seasonality on the chemical composition, antioxidant activity and cytotoxicity of polish propolis in human erythrocytes. Rev Bras Farmacogn. 2019:29:301-8. https://doi.org/10.1016/j.bjp.2019.02.002

30. Rains JL, Jain SK. Oxidative stress, insulin signaling, and diabetes. Free Radic Bio Med. 2011;50:567-75. https://doi.org/10.1016/j.freeradbiomed.2010.12.006.

31. Wu NH, Ke ZQ, Wu S, Yang XS, Chen QJ, Huang ST, Liu C. Evaluation of the antioxidant and endothelial protective effects of Lysimachia christinae Hance (Jin Qian Cao) extract fractions. J Altern Complement Med. 2018;18(1):12835. https://doi.org/10.1186/s12906-018-2157-1.

32. Nauman M, Kale RK, Singh RP. Polyphenols of Salix aegyptiaca modulate the activities of drug metabolizing and antioxidant enzymes, and level of lipid peroxidation. J Altern Complement Med. 2018;18(1):81-93. https://doi.org/ 10.1186/s12906-018-2143-7.

33. Wang HL, Gao JP, Han YL, Xu X, Wu R, Gao Y, Cui XH. Comparative studies of polydatin and resveratrol on mutual transformation and antioxidative effect in vivo. Phytomedicine. 2015;22:553-9. https://doi.org/10.1016/j. phymed.2015.03.014

34. Zhou Y, Tan F, Li C, Li W, Liao W, Li Q, Zhao X. White Peony (Fermented Camellia sinensis) polyphenols help prevent alcoholic liver injury via antioxidation. Antioxidation. 2019;8:524-39. https://doi.org/10.3390/ antiox8110524.

35. Hsieh HM, Wu WM, Hu ML. Soy isoflavones attenuate oxidative stress and improve parameters related to aging and Alzheimer's disease in C57BL/6 J 
mice treated with D-galactose. Food Chem Toxicol. 2009;47:625-32. https:// doi.org/10.1016/j.fct.2008.12.026.

36. Niki E. Assessment of antioxidant capacity in vitro and in vivo. Free Radic Biol Med. 2010:49:503-15. https://doi.org/10.1016/.jreeradbiomed.2010.04.016.

37. Sharifi-Rad J, Sharifi-Rad M, Salehi B, Iriti M, Roointan A, Mnayer D, Afshari A. In vitro and in vivo assessment of free radical scavenging and antioxidant activities of Veronica persica Poir. Cell Mol Biol. 2018;64:57-64. https://doi. org/10.14715/cmb/2018.64.8.9.

38. Fardet $A$, Rock $E$, Rémésy $C$. Is the in vitro antioxidant potential of wholegrain cereals and cereal products well reflected in vivo? J Cereal Sci. 2008;48: 258-76. https://doi.org/10.1016/j.jcs.2008.01.002.

\section{Publisher's Note}

Springer Nature remains neutral with regard to jurisdictional claims in published maps and institutional affiliations.

Ready to submit your research? Choose BMC and benefit from:

- fast, convenient online submission

- thorough peer review by experienced researchers in your field

- rapid publication on acceptance

- support for research data, including large and complex data types

- gold Open Access which fosters wider collaboration and increased citations

- maximum visibility for your research: over $100 \mathrm{M}$ website views per year

At BMC, research is always in progress.

Learn more biomedcentral.com/submissions 